\title{
FORUM
}

\section{Triatominae (Hemiptera: Reduviidae): Systematic Questions and Some Others}

\author{
CARL W. Schaefer \\ Dept. Ecology and Evolutionary Biology, University of Connecticut, U-3043, Storrs CT, 06269-3043, USA \\ e-mail: schaefer@uconnvm.uconn.edu
}

Neotropical Entomology 32(1):001-010 (2003)

Triatominae (Hemiptera: Reduviidae): Questões Sistemáticas e Algumas Outras

\begin{abstract}
RESUMO - Os vetores da doença de Chagas são classificados como membros dos reduviídeos da subfamília Triatominae. Entretanto, essa classificação tem sido referida como incorreta por alguns autores, que consideram que alguns (ou todos?) os grupos de Triatominae têm diferentes ancestrais nãotriatomíneos. Neste artigo essa questão é discutida amplamente e outras questões relacionadas ao tema são também levantadas, em particular a posição sistemática de Linshcosteus, o único gênero de Triatominae que ocorre fora do Novo Mundo (na Índia). Outro exemplo é o fato de diversas espécies e populações terem derivado da espécie tropical Triatoma rubrofasciata (De Geer). A resposta a essas questões - se os triatomíneos têm mais de um ancestral não-triatomíneo e, portanto, seriam filogeneticamente distantes - não tem apenas interesse acadêmico. É impossível generalizar para todos os grupos o que é conhecido apenas para um grupo, e isso pode prevenir o controle desses vetores de doenças. Portanto, é literalmente vital determinar se Triatominae é um grupo holofilético e, se não, quais grupos classificados como triatomíneos são relacionados entre si. Essa determinação poderá ser feita através da análise cladística dos generos atualmente incluídos em Triatominae. Alguns comentários sobre cladística são apresentados em um Apêndice.
\end{abstract}

PALAVRAS-CHAVE: Doença de Chagas, Trypanosoma cruzi, Rhodnius, Linshcosteus, cladística

\begin{abstract}
The Neotropical Chagas' disease vectors are classified as members of the reduviid subfamily Triatominae. However, this classification has been suggested to be incorrect, and the suggestion has been treated as fact by some authors; the suggestion is that some (all?) groups in Triatominae had different nontriatomine reduviid ancestors. In this article I raise this question explicitly and ask other questions ancillary to it. I do not answer these questions. Of particular interest is the systematic position of Linshcosteus, the only genus of Triatominae all of whose species occur outside the New World (in India). Related to this question is that of the origin(s) of the several species and populations probably derived from the tropicopolitan Triatoma rubrofasciata (De Geer). Answering these questions is of more than academic interest, for if triatomines had more than one nontriatomine ancestor, and therefore are not phylogenetically close, it is impossible to generalize what is known about one group to others, and this inability may hinder control of these disease vectors. It is therefore vital (literally!) to determine if Triatominae is a holophyletic group and, if not, to determine which groups now classified as triatomines are related to which others. This determination may best be accomplished with a cladistic analysis of the genera now included in Triatominae. Some comments on cladistics are presented in an Appendix.
\end{abstract}

KEY WORDS: Insecta, Chagas' disease, Trypanosoma cruzi, Rhodnius, Linshcosteus, cladistics

The reduviid subfamily Triatominae is of great interest ecologically and medically: ecologically because it is one of the few major groups of heteropterans that feed on vertebrate blood, and medically because some triatomines are the vectors of Trypanosoma cruzi Chagas, the causative agent of Chagas' disease. The only other major blood-feeding heteropteran groups are Cimicidae (bed bugs) and the related Polyctenidae, ectoparasites of bats; neither contains vectors of human disease (see Schaefer 2000).

Chagas' disease is a serious trypanosomiasis in the New World tropics, and occasionally occurs in the southern United States. It is sometimes fatal and usually very debilitating; the loss to Chagas' disease in human suffering and economics is deep indeed (see Schofield's fine book [1994] and my review 
thereof [Schaefer 1995]). Moreover, as the earth warms, the developmental cycles of both bugs and vectors become shorter (Carcavallo et al. 1998), which will result in more generations per year; also possible is a northern extension of both vectors and pathogens.

Certainly the group is worthy of considerable study, and has received it: much of the work on Triatominae is summarized in the three-volume "Atlas of Chagas' Disease Vectors in the Americas" (Carcavallo et al. 1998-1999); the subfamily has been taxonomically revised by Lent \& Wygodzinsky (1979); and Carcavallo et al. (2000) have summarized taxonomic work subsequent to the 1979 revision, and have presented new ideas on systematics and phylogeny.

\section{Systematic and Phylogenetic Questions}

Yet despite this interest and study, important systematic/ phylogenetic questions remain unanswered and, in some cases, unasked or poorly formulated. I summarize some of these questions here, and try to show why they are important not only for those interested in reduviid systematics, but for those concerned with understanding and controlling Chagas' disease.

Although some of what I say here may seem critical, or even rebarbative, I do not intend to disparage what has been done or those by whom it has been done. Much excellent work on Triatominae has been published. I believe that this work, and the planning of future work, can be placed in a broader and more useful and informative context if certain systematic questions are answered. Among the several questions for which answers are needed are these:

1) How Many Ancestors? Are Triatominae polyphyletic (descended from more than two ancestors) or diphyletic (descended from two ancestors) or, as currently treated, monophyletic? These possibilities have been suggested (Schofield 1988, 2000; Schofield \& Dolling 1993; Schofield \& Dujardin 1999; Bargues et al. 2000), and discussed by Carcavallo et al. (1999, 2000); but the evidence is weak (see below, and Schaefer \& Coscarón 2001), or controverted by other evidence (Hypša et al. 2002).

The most evidence for polyphyly (actually, diphyly) has been gathered by Schofield \& Dujardin (1999) in a paper not seen by Schaefer \& Coscarón (2001). Schofield \& Dujardin write, "Our working hypothesis considers the Triatominae to represent a polyphyletic assemblage of predatory reduviids" (p. 187); and, again, "In fact the Triatomini and Rhodniini appear to derive from different reduviid lineages, and now [why "now": did they once have more in common?] have little in common other than their basic reduviid form overlaid with convergent characters associated with their bloodsucking habit" (p. 188). However, what in 1999 was "our working hypothesis" has become a year later "the Triatominae are clearly polyphyletic" (Schofield 2000, p. 540). Some of the evidence adduced consists of molecular and morphological differences between Rhodniini and Triatominae. Yet nowhere is it stated that these differences indicate separate reduviid origins for the two tribes. For example, Stothard et al. (1997) and Lyman et al. (1999) show clear molecular differences between the two tribes, but none of these differences seems to be (nor does any author say that it is) great enough to suggest separate reduviid origins of the two tribes. The fact that two tribes are recognized, tells us already that they are different - but by how much: by enough to suggest they had separate ancestries? This question can only be answered comparatively, in both (not either) of two ways: Do these tribes differ more greatly from each other than either does from other triatomine groups? And, do these two tribes differ at least as greatly from each other as do separate subfamilies of Reduviidae? The answer to each question must be Yes, even merely to suggest the two tribes had separate non triatomine origins. Perhaps an analogy will help: My brother and I differ, but do we differ enough to conclude that he and I in fact had different parents? The mere fact that we differ does not answer that question.

Bargues et al. (2000) write that "current theory envisages the Triatominae as a polyphyletic assemblage of bloodsucking Reduviidae, with the various lineages probably derived from different predatory ancestors" (p. 570). Discussing how their results support this current theory, they write that "adaptation to haematophagy... may have occurred at different times in the different triatomine lineages" (p. 570). But if these lineages were already triatomine (as Bargues et al. state) at the time of the independent adaptations to hematophagy, then there is no polyphyly. Late in their paper, Bargues et al. (2000) argue the Rhodniini and Triatomini had separate origins, as did also species of Triatoma itself. Of the latter they write, "within the Triatomini, our results also indicate a polyphyletic origin" (p. 571), meaning here the origins of the North and South American species of Triatoma. But there is no suggestion that the ancestor(s) of these groups were nontriatomine. In fact, Bargues et al. (2000) suggest that North and South American Triatoma species each achieved bloodsucking independently from a predaceous ancestor. This is neither diphyly nor polyphyly of Triatominae, unless it is shown that that ancestor was not a triatomine; and this possibility is not mentioned.

Further, if indirect, evidence for polyphyly of triatomines is given as their ability "to develop rapid [sic: rapidly] morphological changes in response to adaptation to new habitats" (Dujardin et al. 1999, p. 226). The connection between rapid adaptation to new habitats and polyphyly, and how the former (a common phenomenon) supports the likelihood of the latter, are not explained.

The statements and suggestions that bloodfeeding in Triatominae has arisen more than once, and that therefore the subfamily is not holophyletic, often appear rather casually certain; moreover, the lack of evidence to support them seems to assume that no such evidence is necessary, so obvious is the fact of separate nontriatomine origins. The assumption seems to be, that that the transition is an easy one: the transition from feeding on other arthropods (most reduviids' way of life) to taking vertebrate blood. Necessary only was the mere availability of vertebrates, in whose burrows or nests those nontriatomine ancestors were already living. (I do not ignore the examples here of the origins of phthirapterans and of certain calyptrate flies [on the latter, 
see Schaefer 1979].) However, on those rare occasions when the putative ancestors of different triatomine groups are named, none is unequivocally associated with vertebrates. Moreover, as Gaunt \& Miles (2000) mention, the transition may be less easy than thought, requiring as it does "the evolution of anti-thrombin, to prevent coagulation interfering with feeding, and of less painful bites to allow prolonged feeding" (p. 563).

Other evidence suggests monophyly of the Triatominae: Perez et al. (1992) found no consistent differences in seven cytogenetic features in the two tribes (Perez et al. 1991, Table II). Hypša et al. (2002) concluded from an analysis of $16 \mathrm{~S}$ and $12 \mathrm{~S}$ rDNA that the subfamily Triatominae is monophyletic, and indeed that the idea Triatomini and Rhodniini had separate origins needs serious reconsideration. And one might suggest that Trypanosoma cruzi is a good taxonomist, and recognizes its hosts as closely related.

I do not insist that Triatominae is monophyletic. I simply ask that authors discussing the subfamily and its members not move beyond the facts. That is, I ask that what is in truth conjecture not be presented as fact. After all, those who have most closely and comprehensively studied the subfamily and its evolution state unequivocally that it is monophyletic (Lent \& Wygodzinsky 1979, see p. 177). This statement does not prove monophyly to be a fact; but by the same token mere assertion that it is false does not make it so.

2) Relationships of relatives of Triatoma rubrofasciata (De Geer). What are the relationships inter se of the derivatives of the tropicopolitan T. rubrofasciata?

2a) If, as seems likely (Patterson et al. 2001), the several Old World species of Triatoma are each derived from a different population of $T$. rubrofasciata, and if these speciations all occurred within the past 200 (Schofield 2000) or 350 years (Patterson et al. 2001), why have not other populations of $T$. rubrofasciata also speciated? That is, selection pressures on some populations of $T$. rubrofasciata must have been far greater than pressures on other populations, so that the former have become sufficiently distinct as to be accorded species status. Other populations, however, in those same 200 or 350 years, remain $T$. rubrofasciata. What are these different selection pressures? Alternatively - but not providing a complete answer - one might suggest there have been repeated invasions of $T$. rubrofasciata from the New World to the Old. Is there evidence (i.e., molecular) for this? Also, why is the idea that Old World Triatoma species evolved from the $T$. rubrofasciata invading from the New World, called "iconoclastic" (Dujardin et al. 1999, p. 224)? This idea seems obvious to me.

2b) Several invasions of the same species, $T$. rubrofasciata, although not impossible, seem a priori unlikely. However, if as Schofield (1988), Schofield and Dolling (1993), and Gorla et al. (1997) suggest, this bug traveled with ship rats, two (or more) invasions of the Old World by this bug from the New World may have occurred. More than one invasion may also explain why some places in the Old World have populations of the species, and other places have species descended from it (see $2 \mathrm{a}$, above). Old World T. rubrofasciata populations often occur near ports
(Gorla et al. 1997, Patterson et al. 2001; and see Cariaso 1968). Do Old World Triatoma species also occur near ports?

2c) What is there about T.a rubrofasciata that only this species has invaded the Old World? If there was but a single invasion, was it by chance? Is the fact that no other species made the move evidence that there was only one such invasion? Or, might some Old World Triatoma species have arisen from some other species, whether another Triatoma or an unrelated reduviid? Patterson et al. (2001) suggest the intriguing possibility that another Triatoma species, $T$. lectularia Stål, also invaded the Old World.

3) Linshcosteus and Triatominae. Is Linshcosteus a true triatomine? That is, does it share with other triatomines a common ancestor which itself would be classified as a triatomine? Several of those supporting the di- or polyphyletic origin of Triatominae believe Linshcosteus at least to have had a separate origin. An analysis of similarity does not quite support this idea (Schaefer \& Coscarón 2001). More important, Hypša et al. (2002) show with molecular data that Linshcosteus and T. rubrofasciata are sister groups and form a clade which "nests firmly within Triatomini" (quote from abstract). Moreover, there is a possibility that Linshcosteus karupus Galvão et al. (Fig. 1) and T. rubrofasciata each harbor the same species of Trypanosoma.

4) Ancestry of Linshcosteus. If Linshcosteus is indeed a triatomine, from what triatomine ancestor has it evolved? If it has evolved from T. rubrofasciata, as the results of Hypša

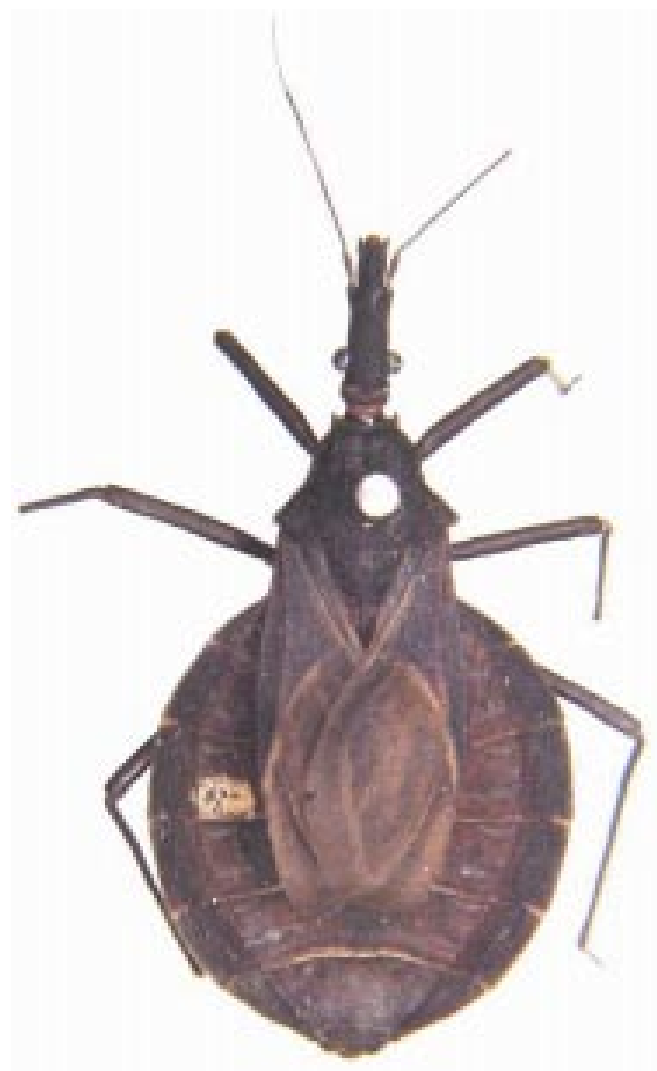

Figure 1. Linshcosteus karupus Galvão et al., dorsal view. 
et al. (2002) suggest, then why has Linshcosteus differentiated so greatly as to be worthy of generic rank, whereas other descendants of $T$. rubrofasciata are "merely" species (and others are simply populations of $T$. rubrofasciata)? Does this cast doubt on the idea that all this differentiation has occurred within a scant 200 or 350 years? Or, conversely, does this suggest that Linshcosteus is descended from an earlier Old World invasion of $T$. rubrofasciata, or from some other triatomine (now extinct?), or from some Old World indigenous nontriatomine?

4a) Might Linshcosteus be descended from some other New World species of Triatoma, or from some other New World triatomine genus, which presumably invaded the Old World sufficiently long ago to have differentiated into a separate genus and then became extinct (see 2c)? A cladistic analysis would help answer this question and many others.

4b) Might Linshcosteus be descended from a nontriatomine (and see 3, above)? That is, might Linshcosteus not be a triatomine at all (Schofield 1988, 2000; Schofield \& Dolling 1993; Gorla et al. 1997)? This possibility has been suggested by many of those who believe Triatominae to be di- or polyphyletic, and who argue that those features of Linshcosteus that link it with Triatominae are merely features any reduviid must acquire if it is to feed on vertebrate blood; Linshcosteus, by this argument, is convergent with members of Triatominae. Schaefer \& Coscarón (2001) discuss this possibility (but do not resolve it), as well as the further possibility that other members of the Triatominae are also included in this subfamily because of convergence, not common ancestry. Here again, phenetic evidence suggests but only suggests - that Linshcosteus is close to triatominae genera (Schaefer \& Coscarón 2001); but again, I believe a cladistic analysis, not a phenetic one, will provide a more convincing answer.

The question of the origin of Linshcosteus is of more than academic interest because, as Schaefer \& Coscarón (2001) have suggested, the chance - however remote - exists that this bug, if a true triatomine, could vector a trypanosomiasis in its homeland (India) as New World triatomines do in theirs (see 3, above).

\section{Significance of the Systematic and Phylogenetic Questions}

More generally, and for much the same reason, the question of the origin(s) of all triatomines should be resolved. Although it has only been suggested that triatomines are polyor diphyletic (see brief discussion in Schaefer \& Coscarón 2001), that suggestion is gradually making its way into the literature as fact. What Schofield and Dujardin (1999) present as a "working hypothesis" (p. 187) becomes for Bargues et al. (2000) a "current theory" (p. 570) and as noted above, for Schofield (2000) a clear fact. Cruz-López et al. (2001) state in their paper's introduction that the Triatominae are "probably" polyphyletic, a statement too strong for the weak evidence upon which it is based. Moreover, however, in its abstract, this same paper states the polyphyly as simple fact: "this polyphyletic subfamily" (p. 351). A paper's abstract is read by more people than the paper itself, and in the case of a medically important group it is read by many nonsystematicists. If this question is not definitely resolved soon, only those who study reduviid systematics will realize that the poly- or diphyly of Triatominae remains unproven, no matter how many times and by how many people it has been suggested or broached. The repeated statement of an unproven fact does not render that fact proven.

Moreover, it has never been stated what groups are or what groups are not true triatomines: Rhodniini and Triatomini are/ may be diphyletic, Triatoma species are/may be di- or polyphyletic, Linshcosteus is not a true triatomine, and in fact there may be no true triatomines, all having been derived (as a group? as two groups? as many groups?) from nontriatomine ancestor(s?). The term "polyphyletic" is used very loosely, almost casually, is not distinguished from "diphyletic," and how either term ought to be applied to Triatominae has never been clearly or comprehensively explicated.

So what? How does this matter? First, of course, it matters because it may not be true. Second, it matters because it says that one or more other reduviid group is not fully defined, because it includes a genus or genera now included in Triatominae. If so, then the definition of that group (subfamily, tribe) of Reduviidae to which the genus or genera belongs must be expanded to include the faux triatomine(s). These are not urgent concerns. Resolving such problems is what systematicists do and, without such problems, systematicists would have to turn to easier work, like lawyering and running countries. A more serious concern is the practical one.

Third, the systematic status of Triatominae matters for the very practical reason that many of these bugs are the vectors of $T$. cruz. Therefore it matters if those triatomines which vector T. cruzi_are related to one another, and it matters further if they - as a group or individually - are related to some other reduviid subfamily or tribe. For a knowledge of the systematics of an organism, which is to say a knowledge of that organism's phylogenetic relationships, tells us a great deal more than where that organism should be placed on a cladogram or phylogenetic tree. After all, it is not just morphological features that are inherited from a common ancestor but often such things as food and habitat preferences, circumstances under which dispersal occurs, means by which mates are attracted, numbers of eggs laid and where, etc. The accuracy of such biological and ecological predictions depends, of course, both on the closeness of the phylogenetic relationship and on the accuracy of the phylogenetic analysis. But if the analysis is a good one, and if its results indicate two groups are closely related, then useful knowledge has been acquired.

Such knowledge allows us to predict, with some degree of accuracy, the biology and ecology of the phylogenetically related groups. Such reasonably accurate predictions in turn may allow us to predict which organisms may become pests on new crops in an area or which organisms may become of medical importance (see Schaefer 1998). Of greater relevance here, such knowledge may help predict the habits and habitats and preferences of groups of which we lack direct knowledge: preferences for bird or mammalian blood; for sylvatic or peridomestic habitats, ground litter or arboreal or shrub habitats; eggs laid separately or in a group, semelparously or 
iteroparously; stage(s) at which dispersal occurs (and if it does) and conditions (dry, wet, warm, cool, combination of these, etc.) under which it occurs; semiochemicals that may influence behavior of another species (allomones) (see CruzLópez et al. 2001); means by which food is detected, sought, and extracted; more generally, how external influences, biotic and abiotic, are detected and responded to (cf. Lorenzo et al. 1999); and so on. In short, a knowledge of phylogenetic relationships provides us with a wealth of predictive and prospective information.

However, here, with triatomines, this information is unavailable to us because we do not know these phylogenetic relationships, particularly those that might suggest polyphyly or diphyly of Triatominae. If the vectors of $T$. cruzi are related to Group A, then one might look to the biology and ecology of members of Group A for clues to the control of those vectors. If some, but not all, of those vectors are related to Group A, then looking to Group A's members for such clues will be fruitless in the control of those vectors not related to Group A; and it is therefore necessary to separate the two groups of vectors, and to determine the relationship(s) of those not related to Group A. Moreover, studying one group of vectors and trying to apply that knowledge to the other, may be a waste of time and money (and hope), if the two groups are not related. More simply put, if triatomine $\mathrm{X}$ is a vector and triatomine $\mathrm{Y}$ is not, we will learn little about $\mathrm{X}$ by studying $\mathrm{Y}$, should $\mathrm{Y}$ prove not to be related to $\mathrm{X}$. Yet considerable work on the biologies and ecologies of triatomine species has been done and is underway. How much of that work's results can be applied to other triatomines?

For example, a promising tool for predicting distributional relationships of organisms is ecologic niche modeling. Peterson et al. (2002) have used it to seek overlaps in the distributions of members of the Triatoma protracta (Uhler) complex and their Neotoma (woodrat) hosts, and thus to predict where Chagas vector and reservoir may occur together. Ryckman's earlier (1962) study provided the data against which the results of Peterson et al. were checked. However, in other studies where ecologic niche modeling may be used, there may be no outside set of data for checking; and indeed the data for the group under study may themselves be incomplete. But if the phylogenetic relationships of the group's members are known, it may be possible to extend data from the known members to the unknown members. How reliably such data can be extended depends of course on how reliable the phylogenetic - cladistic - analysis is, and on how close phylogenetically the group's members are. The better the phylogenetic information, the better the inferences; the better the inferences, the more useful as a predictor will be the results of ecologic niche modeling.

Therefore it seems to me imperative that the question of di- or polyphyly of Triatominae be resolved and to remove from Triatominae those groups unrelated to it. No-one has done this, except to suggest that Linshcosteus might be removed. But if Linshcosteus is the only nontriatomine, then the subfamily is diphyletic, not polyphyletic as Cruz-López et al. (2001) so unambiguously assert in their abstract, and as so many other papers strongly suggest (see references in 1 , above).

I submit that these are not abstruse arguments difficult to grasp: they are quite obvious. Nevertheless, the importance of actually determining the phylogenetic affinities of the triatomine genera seems not to have been stressed, except by Hypša et al. (2002). Moreover, as I have written above, the idea may be spreading that the Triatominae are poly- or diphyletic, an idea which suggests (to repeat myself for emphasis) that studying nonvector triatomines is of little value in controlling the vectors. The idea suggests also - in the absence of a good idea of what nontriatomine these vectors may be related to - that we have no idea what groups to study. We do of course study the vectors themselves, but in the absence of a good phylogeny, we survey an unnecessarily limited landscape of possibilities.

\section{Cladistics}

Perhaps some of these problems and unasked questions exist because few working on these bugs are taxonomists. Perhaps a lack of "systematic sophistication" helps explain the unsupported assertion that Triatominae are polyphyletic (Cruz-López et al. 2001), the apparent belief that if two groups are quite different they could not have had a common ancestor, and the resulting confusion between di- and polyphyly (as discussed in Schaefer \& Coscarón [2001]) and the lack of solid evidence for either. (See the Appendix for a brief account of cladistics.)

Perhaps a further, and equally partial, explanation lies in the fact that there has yet to be made a cladistic analysis of the genera of Triatominae. The large literature on generic and tribal relationships consists nearly entirely of morphometric and molecular analyses. Morphometry is essentially an analysis of similarity, a phenetic analysis, not greatly different from although considerably more sophisticated than - the analysis by Schaefer \& Coscarón (2001). Such techniques are excellent for describing what is but, for the most part, less good at convincingly describing how what is has come to be: The present is not easily derived from the past. (The basis for these comments can be found here and there throughout the various papers in Sorensen \& Foottit [1992a].) Similarity can be quite deceiving and, no matter how subtlely, moving from morphometry to phylogeny is a long and slippery step. Molecular analyses also are difficult to analyze for phylogenetic conclusions; and of course analyses based on different molecules may (and do) yield different results (just as will analyses based on different single morphological characters). The occasional difficulty of reconciling molecular results with other types of results (e.g., geological) is exemplified in the last paragraph of Schofield (2000).

Nevertheless, attempts are being made to work out phylogenies from morphometric data (Sorensen \& Foottit 1992b), and these attempts have been applied (Roskam \& Zandee 1992, Wood \& Pesek 1992, Patterson et al. 2001). However, as Roskam \& Zandee write, "because phylogenetic arguments emerge from a more sound theoretical base than phenetics, we feel they should play the prevailing role in determining past evolutionary scenarios" (1992, p. 345). The best test of a morphometrically generated phylogeny is a comparison with a cladistic one. This is exactly what I urge here.

Cladistic analyses seek specifically for the most recent 
common ancestor, and do so using all data, and all categories of data, available. No better kind of analysis has been devised for answering just such questions as I have suggested above need to be answered.

Finally, what may indicate to some a di- or polyphyletic origin of Triatominae or of some included group, may in fact be paraphyly, as discussed by Hypša et al. (2002); see also Stothard et al. (1998), Monteiro et al. (2001), and Garcia et al. (2001), for possible paraphyly of Triatoma. This possibility may explain why Bargues et al. (2000) believe Triatoma itself is polyphyletic, and Marcilla et al. (2002) believe the same of Panstrongylus. A cladistic analysis would help answer this question.

\section{Some Ecological Questions}

Although I am concerned here with systematic and phylogenetic questions, there are of course many ecological ones as well. One is the role (if any) and specificity (if any) of pheromones in Triatominae. There is a body of literature on the subject as remarkable for its size as for its ambiguity and contradictory results (see review by Cruz-López et al. 2001). Females of one species attract males (Ondarza et al. 1986), or they do not (Rojas et al. 1991). Males and females of another species attract one another (Neves \& Paulini 1981), but Lima \& MacCord (1994) found no attractive odor, but Lima et al. 1986) showed females attract males but (presumably) not the reverse. Clearly, much needed are wellcontrolled studies whose parameters and conditions mirror those that actually occur in nature. Equally clearly, we need to know if the species studied are in fact related to one another.

Nymphs of many species apparently are attracted to the feces of adults and other nymphs (reviewed by Cruz-López et al. 2001). This is understandable because nymphs, being flightless, are less able than adults to seek food. But it is less clear to what extent adults of any species are attracted by feces or by a nonsex-attractant pheromone. Such an attraction would seem to make sense, because feces are produced during or just after feeding, the food source almost always contains more food (blood) than one bug can consume, and the disadvantage of vying for food is therefore less and the advantages of aggregation are more.

One such advantage is of course the arrival to a food source of potential mates, and the mating there of females ready to turn blood into fertilized eggs. Another advantage (perhaps) is the collective security provided by a group of bugs. Disturbed bugs produce isobutyric acid and other apparently defensive compounds from their Brindley's glands (review in Cruz-López et al. 2001). A group of bugs would produce more of these compounds, and thus provide to each member a higher degree of security. More commonly, insects that group together for collective protection are aposematic. But many triatomines feed at night, and often, I assume, the enemy against which they protect themselves is the food source itself. Might the collective production of defense allomones be considered olfactory aposematicism? One test of this idea might be to study the kinds and amounts of defense allomones of diurnal as opposed to nocturnal species.

Helping in these studies would be a far better knowledge of the various exocrine glands in triatomine bugs, their activities in each sex and in nymphs, and their products. Some such studies exist for individual species (e.g., Fontana et al. 2002, Rojas et al. 2002), but it is not always clear what glands(s) produce the semiochemicals (Fontana et al. 2002), or how widely results can be generalized. I should mention also that Brindley's glands occur only in Reduviidae, and heteropterists in general would like to know more about their function(s).

Another complementary study should be of the possible warning of triatomine (and other reduviid) stridulations. Schilman et al. (2001) make the fascinating suggestion that the apparently species-nonspecific stridulations of triatomines function as a kind of auditory aposematicism, warning possible predators that the bugs with their isobutyric acid are distasteful. This view of triatomine stridulation is indirectly supported by the fact that in Triatoma infestans (Klug) (Roces \& Manrique 1996) (Fig. 2) and in Rhodnius prolixus Stål (Manrique \& Schilman 2000), both sexes produce disturbance stridulations, and unreceptive females produce a different stridulation to repel unwanted male attention.

Overgeneralization may account for some of the ambiguity and apparent contradiction in the literature. The biology and ecology and behavior of many different species of Triatominae have been, and are being, studied individually, and there may be a tendency to generalize from each study to other species and even genera. If so, the generalizations will be contradictory just to the extent that a studied species differs from those to

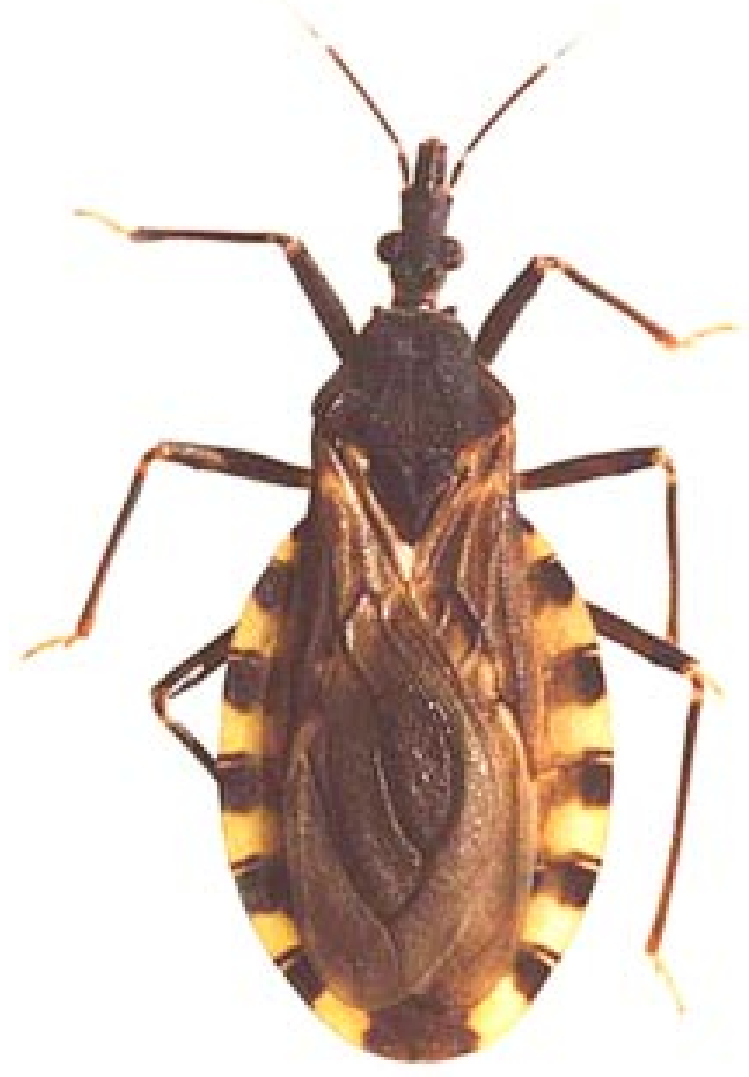

Figure 2. Triatoma infestans (Klug), dorsal view. 
which its biology is generalized (I do not imply di- or polyphyly!). The degree of difference, and thus the validity of the generalization, depends upon the phylogenetic closeness of the species' genera involved. And so (I say it once again) systematic and phylogenetic work is necessary. This argument is far more forceful if in fact the Triatominae are not holophyletic, for then some generalizations are meaningless.

\section{Acknowledgments}

I am deeply grateful to Cleber Galvão (Instituto Oswaldo Cruz, Rio de Janeiro, Brazil), and to Antônio Panizzi (Embrapa Soja, Londrina, Brazil) for their close and critical reading of this paper; to Antônio Panizzi again for helping to shepherd the paper through the press and for the Portuguese abstract; to Cleber Galvão again for the lovely photographs. Finally, I owe a large debt of gratitude to Derek Sikes, of my department, for a thorough analysis and discussion of the Appendix.

\section{Literature Cited}

Ashlock, P.D. 1971. Monophyly and related terms. Syst. Zool. 20: 63-69.

Bargues, M.D., A. Marcilla, J.M. Ramsay, J.-P. Dujardin, C.J. Schofield \& S. Mas-Coma. 2000. Nuclear rDNAbased molecular clock of the evolution of Triatominae (Hemiptera: Reduviidae), vectors of Chagas disease. Mem. Inst. Oswaldo Cruz 95: 67-573.

Carcavallo, R.U., C. Galvão, D. da Silva Rocha, J. Jurberg \& S.I.C. de Casas. Predicted effects of warming on Chagas' disease vectors and epidemiology. Entomol. Vect. 5: 137-138.

Carcavallo, R.U., I.G. Girón, J. Jurberg \& H. Lent. 19981999. Atlas of Chagas' disease vectors in the Americas. Vol. I, II, III. Rio de Janeiro, Brazil, Editora Fiocruz, $1217 \mathrm{p}$.

Carcavallo, R.U., J. Jurberg \& H. Lent. 1999. Phylogeny of the Triatominae, p. 925-969. In R.U. Carcavallo, I.G. Girón, J. Jurberg \& H. Lent (eds.), Atlas of Chagas' disease vectors in the Americas, vol. III. Rio de Janeiro, Brazil, Editora Fiocruz, 1217p.

Carcavallo, R.U., J. Jurberg, H. Lent, F. Noireau \& C. Galvão. 2000. Phylogeny of the Triatominae (Hemiptera: Reduviidae). Proposal for taxonomic arrangements. Entomol. Vect. 7 (Suplemento 1): 1-99.

Cariaso, B.L. 1968. Notes on Triatoma rubrofasciata De Geer (Reduviidae: Hemiptera) in the Philipines. Philip. J. Entomol. 1: 172-174.

Cruz-López, L., E. A. Malo, J. C. Rojas \& E. D. Morgan. 2001. Chemical ecology of triatomine bugs: vectors of Chagas disease. Med. Vet. Entomol. 15: 351-357.
Dujardin, J.P., P. Panzera \& C.J. Schofield. 1999. Triatominae as a model of morphological plasticity under ecological pressure. Mem. Inst. Oswaldo Cruz 94 Suppl. 1: 223-228.

Fontana, A., P.G. Audino, A. Martinez, R.A. Alzogaray, E.N. Zerba, F. Camps \& Cork. 2002. Attractant volatiles released by female and male Triatoma infestans (Hemiptera: Reduviidae), a vector of Chagas disease: chemical analysis and behavioral bioassay. J. Med. Entomol. 39: 191-197.

Galvão, C., J.S. Patterson, D. da Silva Rocha, J. Jurberg, R. Carcavallo, K. Rajen, D.P. Ambrose \& M.A. Miles. 2002. A new species of Triatominae from Tamil Nadu, India. Med. Vet. Entomol. 16: 1-8.

García, B.A., E.N. Moriyama \& J.R. Powell. 2001. Mitochondrial DNA sequences of triatomines (Hemiptera: Reduviidae): phylogenetic relationships. J. Med. Entomol. 38: 675-683.

Gaunt, M. \& M. Miles. 2000. The ecotopes and evolution of triatomine bugs (Triatominae) and their associated trypanosomes. Mem. Inst. Oswaldo Cruz 95: 557-565.

Gorla, D.E., J.P. Dujardin \& C.J. Schofield. 1997. Biosystematics of Old World Triatominae. Acta Tropica 63: $127-140$.

Hypša, V., D.F. Tietz, J. Zrzavý, R.O.M. Rego, C. Galvão \& J. Jurberg. 2002. Phylogeny and biogeography of Triatominae (Hemiptera: Reduviidae): molecular evidence of a New World origin of the Asiatic clade. Molec. Phylog. Syst. 23: 447-457.

Lent, H. \& P. Wygodzinsky. 1979. Revision of the Triatominae (Hemiptera: Reduviidae), and their significance as vectors of Chagas' disease. Bull. Amer. Mus. Nat. Hist. 163: 127-520.

Lima, M.M. \& J.R. MacCord. 1994. Possible absence of attraction to odors in Panstrongylus megistus (Hemiptera: Reduviidae) under laboratory conditions. Mem. Inst. Oswaldo Cruz 86: 271-274.

Lima, M.M., P. Jurberg \& J.R. de Almeida. 1986. Behavior of triatomines (Hemiptera: Reduviidae) vectors of Chagas' disease. I. Courtship and copulation of Panstrongylus megistus (Burmeister, 1835) in laboratory conditions. Mem. Inst. Oswaldo Cruz 81: $1-5$.

Lorenzo, M.G., G.B. Flores, C.R. Lazzari \& C.E. Reisenman. 1999. Sensory ecology. A - Orientation, p. 1071-1087. In R.U. Carcavallo, I. Galíndez Girón, J. Jurberg, and H. Lent (eds.), Atlas of Chagas' disease vectors in the Americas, vol. III. Rio de Janeiro, Brazil, Editora Fiocruz, 1217p. 
Lyman, D.F., F.O. Monteiro, A.E. Escalante, C. CordonRosales, D.M. Wesson, J.-P. Dujardin \& C.B. Beard. 1999. Mitochondrial DNA sequence variation among triatomine vectors of Chagas' disease. Amer. J. Trop. Med. Hyg. 60: 377-386.

Manrique, G. \& P.E. Schilman. 2000. Two different vibratory signals in Rhodnius prolixus (Hemiptera: Reduviidae0. Acta Trop. 77: 271-278.

Marcilla, A., M.D. Bargues, F. Abad-Franch, F. Panzera, R.U. Carcavallo, F. Noireau, C Galvão, J. Jurberg, M.A. Miles, J.-P. Dujardin \& S. Mas-Coma. 2002. Nuclear rDNA ITS-2 sequences reveal polyphyly of Panstrongylus species (Hemiptera: Reduviidae: Triatominae), vectors of Trypanosoma cruzi. Infection, Genetics and Evolution 1: 225-235.

Monteiro, F.A., A.A. Escalante \& C.B. Beard. 2001. Molecular tools and triatomine systematics: a public health perspective. Trends Parasitol. 17: 344-347.

Neves, D.P. \& E. Paulini. 1981. Atracão sexual en Panstrongylus megistus e Triatoma infestans (Hemiptera: Rduviidae) por feromonio. Rev. Bras. Entomol. 25: 301-306.

Ondarza, R.N., A. Gutierrez-Martinez, \& E.A. Malo. 1986. Evidence of the presence of sex and aggregation phermones from Triatoma mazzotti (Hemiptera: Reduviidae). J. Econ. Entomol. 79: 688-692.

Patterson, J.S., C.J. Schofield, J.-P. Dujardin \& M.A. Miles. 2001. Population morphometric analysis of the tropicopolitan bug Triatoma rubrofasciata and relationships with Old World species of Triatoma: evidence of New World ancestry. Med. Vet. Entomol. 15: 443-451.

Perez, R., Y. Panzera, S. Scafiezzo, M.C. Mazzella, F. Panzera, J.-P. Dujardin \& E. Scvortzoff. 1992. Cytogenetics as a tool for triatomine species distinction (Hemiptera: Reduviidae). Mem. Inst. Oswaldo Cruz 87: 353-361.

Peterson, A.T., V. Sánchez-Cordero, C.B. Beard \& J.M. Ramsey. 2002. Ecologic niche modeling and potential reservoirs for Chagas disease, Mexico. Emerging Infect. Dis. 8: 662-667.

Roces, F. \& G. Manrique. 1996. Different stridulatory vibrations during sexual behaviour and disturbance in the bloodsucking bug Triatoma infestans (Hemiptera: Reduviidae). J. Insect Physiol. 42: 231-238.

Rojas, J.C., E. Rios-Candelaria, L. Cruz-López, A. Santiesteban, J.G. Bond-Compean, Y. Brindis \& E.A. Malo. 2002. A reinvestigation of Brindley's gland exocrine compounds of Rhodnius prolixus (Hemiptera:
Reduviidae). J. Med. Entomol. 39: 256-265.

Roskam, J.C. \& M. Zandee. 1992. Phylogenetic analysis of quantitative and qualitative characters of gall-inducing midges and the historical relation to their hosts: Dasineura (Diptera: Cecidomyiidae) on Rosaceae and monocots, p. 325-347, In J.T. Sorensen \& R. Foottit (eds). 1992. Ordination in the study of morphology, evolution and systematics of insects. Amsterdam, The Netherlands, Elsevier, 418p.

Ryckman, R.E. 1962. Biosystematics and hosts of the Triatoma protracta complex in North America (Hemiptera: Reduviidae) (Rodentia: Cricetidae). Univ. Calif. Publ. Entomol. 27: 93-240.

Schaefer, C.W. 1979. Feeding habits and hosts of calyptrate flies (Diptera: Brachycera: Cyclorrhapha). Entomol. Gen. 5: 193-200.

Schaefer, C.W. 1995. [review of Schofield 1994]. J. Med. Entomol. 32: 911-912.

Schaefer, C.W. 1998. Phylogeny, systematics, and practical entomology: the Heteroptera (Hemiptera). An. Soc. Entomol. Brasil 27: 499-511.

Schaefer, C.W. 2000. Bed bugs (Cimicidae), p. 519-538. In C.W. Schaefer \& A.R. Panizzi (eds.), Heteroptera of economic importance. Boca Raton, Florida, CRC Press, $828 \mathrm{p}$.

Schaefer, C.W. \& M.C. Coscarón. 2001. The status of Linshcosteus in the Triatominae (Hemiptera: Reduviidae). J. Med. Entomol. 38: 862-867.

Schilman, P.E., C.R. Lazari \& G. Manrique. 2001. Comparison of disturbance stridulations in five species of triatomine bugs. Acta Trop. 79: 171-178.

Schofield, C.J. 1988. Biosystematics of the Triatominae, p. 285-312. In M.W. Service (ed.), Biosystematics of Haematophagous Insects. Oxford, England, Clarendon, $363 \mathrm{p}$.

Schofield, C.J. 1994. Triatominae: Biology and Control. Bognor Regius, England, Eurocommunica Publications, 79p.

Schofield, C.J. 2000. Trypanosoma cruzi - the vector-parasite paradox. Mem. Inst. Oswaldo Cruz 95: 535-544.

Schofield, C.J. \& J.P. Dujardin. 1999. Theories on the evolution of Rhodnius. Actual Biol. 21: 183-197.

Schofield, C.J. \& W.R. Dolling. 1993. Bedbugs and kissing-bugs (bloodsucking Hemiptera), p. 483-516. In R.P. Lane \& R.W. Crosskey (eds.), Medical insects and arachnids. London, England, Chapman and Hall, $723 \mathrm{p}$. 
Sorensen, J.T. \& R. Foottit (eds.). 1992a. Ordination in the study of morphology, evolution and systematics of insects. Amsterdam, The Netherlands, Elsevier, 418p.

Sorensen, J.T. \& R. Foottit. 1992b. The evolutionary quantitative genetic rationale for the use of ordination analyses in systematics: phylogenetic implications, $\mathrm{p}$. 29-53. In J.T. Sorensen \& R. Foottit (eds). 1992. Ordination in the study of morphology, evolution and systematics of insects. Amsterdam, The Netherlands, Elsevier, 418p.

Stothard, J.R., Y. Yamamoto, A. Cherchi, A.L. Garcia, S.A.S. Valente, C.J. Schofield \& M.A. Miles. 1998. A preliminary survey of mitochondrial sequence-variation in Triatominae (Hemiptera: Reduviidae) using polymerase chain reaction-based single strand conformational polymorphism (SSCP) analysis and direct sequencing. Bull. Entomol. Res. 88: 553-560.

Wood, T.K. \& J.D. Pesek. 1992. Pronotal shape: a source of confusion or panacea in systematic studies of treehoppers (Homoptera: Membracidae)?, p. 349-385. In J.T. Sorensen \& R. Foottit (eds). 1992. Ordination in the study of morphology, evolution and systematics of insects. Amsterdam, The Netherlands, Elsevier, 418p.

\section{Appendix Some Cladistic Terms}

Here I shall mention briefly what cladistics is and how it is used, as well as some common terms used by cladists to describe different types of classifications (monophyletic, polyphyletic, paraphyletic). I shall not consider how a cladistic analysis is constructed and how a cladogram (or phylogenetic tree) is generated.

Cladistics is a method by which ancestor-descendent (phylogenetic) relationships are inferred; it is also the study of such relationships. It is important to realize that a cladistic analysis, usually expressed in a diagram (a cladogram; see Fig. 3), is a hypothesis, not a proven conclusion. It is therefore always subject to further testing, and further testing of a cladogram is always encouraged as new data become available on the organisms in question, and as additional organisms become available.

Analysis of these ancestor-descendent relationships is based on study of existing organisms, fossils of most groups being so scarce; the analysis consists of inferring what the relationship is between characters of the organisms being studied, and those of their ancestors. Thus the analysis is, and must always be, hypothetical (hence "hypothesis") and somewhat abstract. By studying existing organisms, one seeks to discover what they have in common (that is, what characters they have in common), and thus to deduce what their common ancestor was like; the assumption of course is that those characters held in common by these organisms were inherited from that common ancestor. In other words, the search is for homologous characters, characters possessed by different organisms as a result of having been

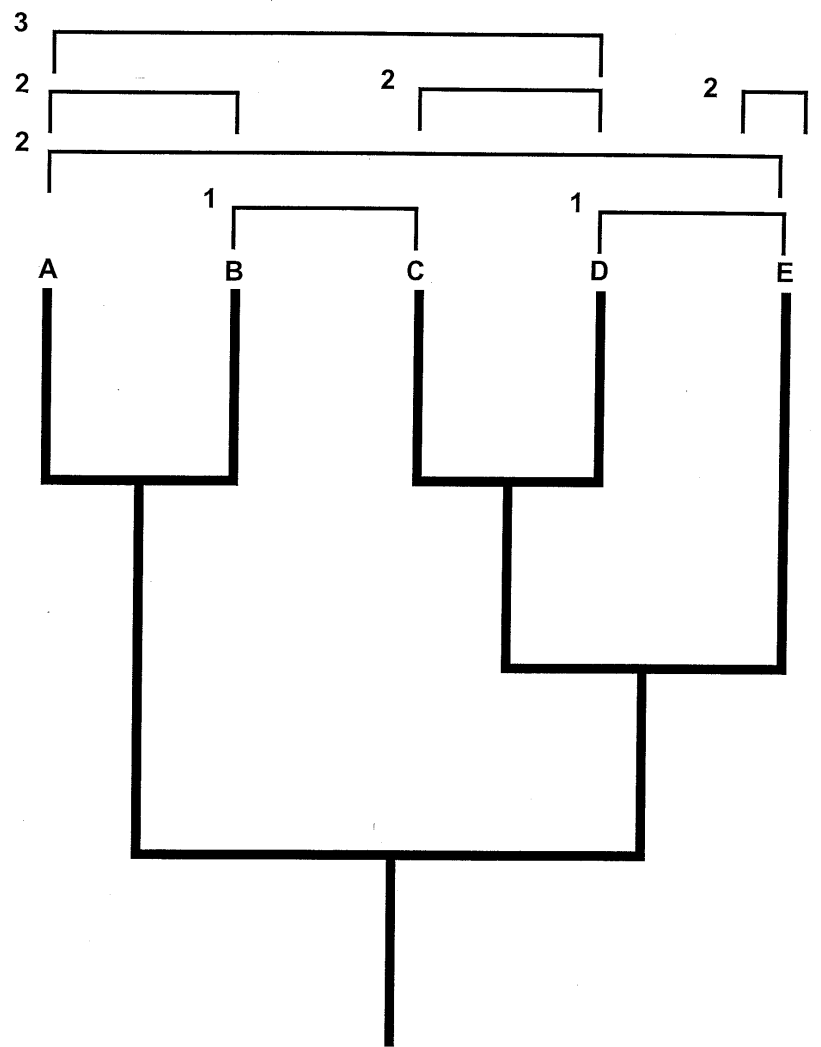

Figure 3. A sample cladogram. A, B, C, D, E = terminal taxa. $1(\mathrm{~B}+\mathrm{C})$ and $(\mathrm{D}+\mathrm{E})=$ polyphyletic (diphyletic) taxa. 2 $(\mathrm{A}+\mathrm{B}+\mathrm{C}+\mathrm{D}+\mathrm{E}),(\mathrm{A}+\mathrm{B}),(\mathrm{C}+\mathrm{D})$, and $\mathrm{E}=$ monophyletic taxa. $3(\mathrm{~A}+\mathrm{B}+\mathrm{C})$ and $(\mathrm{C}+\mathrm{D}+\mathrm{E})=$ paraphyletic taxa.

inherited from that common ancestor. However, if a trait or character found in two different organisms was inherited from a more distant ancestor than the most immediate one, then other organisms as well may have the character and, more important, it becomes unclear just how closely related the two organisms are. For example, a mouse and a jaguar both have hair. They are not closely related, however, because the common ancestor from which each inherited hair, is the distant ancestor of all mammals - of mice and jaguars, and of all other mammals as well.

Thus cladistics seeks the most recent ancestor of the organisms under study, not just any ancestor. A close analogy is the study of genealogy: The immediate "ancestors" of one's self and one's siblings, are one's parents. Features common to one's self, one's siblings, and to one's cousins are features not inherited from one's parents but, more probably, from one's grandparents - not the most immediate "ancestors." These common features cannot distinguish between one's siblings and one's cousins, and therefore do not group one's self plus one's siblings as a single unit (or clade). Only those features inherited from one's parents, the most immediate ancestors, can provide that distinction.

The next step is to determine the common ancestor of the common ancestors one has already hypothesized - that is, to discover the parents of the parents (the grandparents); and then the grandparents' parents (the great grandparents); and 
so on. Cladistics thus works further and further back genealogically, which is to say, further and further back in time, gathering together ancestors, and clusters of ancestors, more and more remote, and including more and more descendent lines. These clusters (for example, all great grandparents, all great great grandparents) may be grouped as named taxa (genera, tribes, etc.), or they may not. Systematics is not the same as cladistics, and some systematicists choose not to base their classifications on cladistic analyses.

However, those who choose to base classifications on cladistic hypotheses must avoid several kinds of error. These errors often result from incorrect or incomplete analyses and are therefore based on false hypotheses, which can be improved (if detected) by further analysis of more data. Two very common errors arise from difficulties with the common ancestor of the taxa (groups) in question.

First, and most simply, organisms which in fact have different ancestors, may for any of several reasons be grouped together as if they in fact had a common ancestor. These are polyphyletic groups (or, if there are but two separate ancestors, diphyletic groups, as in Fig. 3, groups $\mathrm{B}+\mathrm{C}$ and $\mathrm{D}+\mathrm{E})$. In Fig. 3, for example, groups $\mathrm{B}$ and $\mathrm{C}$ may more closely resemble one another than either resembles A or D. In this case similarity of appearance does not reflect common ancestry, and if B and C are grouped together systematically an error has been made. The same argument may hold for groups D and E.

The second type of error is more subtle. For any of several reasons, a group may not include all descendents of the common ancestor. In Fig. 3, group $\mathrm{A}+\mathrm{B}+\mathrm{C}+\mathrm{D}$ does indeed have a common ancestor, but group $\mathrm{E}$ is also descended from that ancestor yet is not included. Group $A+B+C+D$ is therefore paraphyletic.

Paraphyletic groups are in fact monophyletic, because their members are all descended from a single (common) ancestor. For this reason, Ashlock (1971) coined the term holophyletic for those monophyletic groups, which contain all descendents of the common ancestor. This term, although very useful, has not been widely accepted; and monophyletic is usually used in the more restricted sense of Ashlock's holophyletic. I so use it in this paper.

Because paraphyletic groups do not include all the descendents of the common ancestor, some (not all) systematicists believe paraphyletic groups should not be named formally; other systematicists disagree. In some cases, one descendent group may be very different from the others (the result perhaps of greater anagenetic change in that group than in its sibling groups); some believe that that group should be accorded formal systematic status equal to that of its sibling groups taken together; and those sibling groups then become a paraphyletic taxon (for example, $\mathrm{A}+\mathrm{B}+\mathrm{C}+\mathrm{D}$ in Fig. 3, in which nonincluded group $\mathrm{E}$ may be supposed to differ markedly from the rest). Systematicists who name paraphyletic groups should be aware of what they are doing and should explicitly justify the action.

I hope recognition of these generally accepted ideas and uses will make easier and more standard discussion of the classification of the Triatominae. No proposed classification should be a based in any way on polyphylies (or diphylies); and if a proposed classification is at all paraphyletic, that fact should be clearly stated and justified. 